\title{
Prognostic significance of plasma bilirubin in sickle cell diseases
}

\author{
Mehmet Rami Helvaci (1) \\ Atilla Yalcin (1) \\ Zeki Arslanoglu (2) \\ Mehmet Duru (3) \\ Abdulrazak Abyad (4) \\ Lesley Pocock (5) \\ (1) Specialist of Internal Medicine, MD \\ (2) Specialist of Dentistry, Ph \\ (3) Specialist of Emergency Medicine, MD \\ (4) Middle-East Academy for Medicine of Aging, MD \\ (5) medi+WORLD International
}

Corresponding author:

Prof Dr Mehmet Rami Helvaci

07400, ALANYA, Turkey

Phone: 00-90-506-4708759

Email: mramihelvaci@hotmail.com

Received September 2020. Accepted October 2020. Published December 1, 2020.

Please cite this article as: Mehmet Rami Helvaci et al. Prognostic significance of plasma bilirubin in sickle cell diseases. Middle East J Intern Med 2020; 13(3): 7-13 DOI: 10.5742/MEJIM2020.93792

\section{ABSTRACT}

Background: Total bilirubin value of the plasma may have prognostic significance in sickle cell diseases (SCD).

Methods: All patients with the SCD were included between March 2007 and June 2016.

Results: We studied 253 patients (128 females) with a plasma bilirubin value of lower than 5.0 $\mathrm{mg} / \mathrm{dL}$ and 109 patients (43 females) with a value of $5.0 \mathrm{mg} / \mathrm{dL}$ and higher. There were 31 deaths during the ten-year period ( 14 females with a mean age of 33.3 and 17 males with a mean age of 30.2 years, $p>0.05$ ). Although the similar mean ages ( 30.2 versus 31.7 years, $p>0.05$ ), male ratio $(60.5 \%$ versus $49.4 \%, p<0.05)$, ileus $(3.9 \%$ versus $10.0 \%, \mathrm{p}<0.01)$, digital clubbing $(6.3 \%$ versus $26.6 \%, \mathrm{p}<0.001)$, leg ulcers $(12.2 \%$ versus $20.1 \%, \mathrm{p}<0.05)$, pulmonary hypertension $(9.4 \%$ versus $23.8 \%, \mathrm{p}<0.001)$, cirrhosis $(1.5 \%$ versus $15.5 \%, \mathrm{p}<0.001)$, chronic renal disease (CRD) $(6.7 \%$ versus $12.8 \%, p<0.05)$, and exitus $(4.7 \%$ versus $11.9 \%, \mathrm{p}<0.001)$ were all higher in patients with the plasma bilirubin value of $5.0 \mathrm{mg} / \mathrm{dL}$ and higher.
Conclusion: SCD are severe inflammatory processes on vascular endothelium, particularly at the capillary level and terminate with accelerated atherosclerosis induced end-organ failures in early years of life. Total bilirubin value of the plasma may have prognostic significance due to the higher prevalence of ileus, digital clubbing, leg ulcers, pulmonary hypertension, cirrhosis, CRD, and exitus in patients with the plasma bilirubin value of $5.0 \mathrm{mg} / \mathrm{dL}$ and higher. The higher bilirubin values may either show the severity of hemolytic process initiated at birth or an advanced hepatic involvement in such cases.

Key words: Sickle cell diseases, plasma bilirubin, chronic endothelial damage, accelerated atherosclerosis, end-organ failure, metabolic syndrome, early aging 


\section{Introduction}

Chronic endothelial damage may be the leading cause of aging by causing disseminated tissue hypoxia all over the body. Probably whole afferent vasculature including capillaries are mainly involved in the process since much higher blood pressures (BP) of the afferent vasculature may be the major underlying cause by inducing recurrent endothelial injuries. Thus the term of venosclerosis is not as famous as atherosclerosis in the literature. Secondary to the chronic endothelial damage, inflammation, edema, and fibrosis, vascular walls become thickened, their lumens are narrowed, and they lose their elastic nature which reduces blood flow and increases systolic BP further. Some of the well-known accelerators of the atherosclerotic process are sedentary lifestyle, physical inactivity, excess weight, smoking, alcohol, cancers, and chronic inflammatory and infectious processes including sickle cell diseases (SCD), rheumatologic disorders, and tuberculosis for the development of irreversible endpoints including obesity, hypertension (HT), diabetes mellitus (DM), peripheric artery disease (PAD), chronic obstructive pulmonary disease (COPD), pulmonary hypertension, chronic renal disease (CRD), coronary heart disease (CHD), cirrhosis, osteoporosis, and stroke, all of which terminate with early aging and premature death. They were discussed under the titles of metabolic syndrome, aging sydrome, and accelerated endothelial damage syndrome in the literature, extensively (1, $2)$. Although early withdrawal of the causative factors may delay terminal endpoints, the endothelial changes cannot be reversed completely after the development of obesity, HT, DM, PAD, COPD, pulmonary hypertension, CRD, CHD, or stroke due to their fibrotic nature $(3,4)$. Similarly, SCD are severe inflammatory processes on vascular endothelium, particularly at the capillary level and terminate with accelerated atherosclerosis induced end-organ failures in early years of life. Total bilirubin value of the plasma may have prognostic significance in the SCD.

\section{Material and Methods}

The study was performed in the Medical Faculty of the Mustafa Kemal University between March 2007 and June 2016. All patients with the SCD were included into the study. The SCD are diagnosed with hemoglobin electrophoresis performed via high performance liquid chromatography. Medical histories including transfused units of red blood cells (RBC) in their lives, surgical operations, medical emergencies, leg ulcers, and stroke were learnt. A complete physical examination was performed by the same internist. Body weight and height were measured, and body mass index (BMI) of each case was calculated by the Same Physician instead of verbal expressions. Weight in kilograms is divided by height in meters squared (5). Patients with disseminated teeth loss ( $<20$ teeth present) were detected. Digital clubbing is diagnosed with the ratio of distal phalangeal diameter to interphalangeal diameter which is greater than 1.0, and with the presence of Schamroth's sign $(6,7)$. Cases with acute painful crisis or any other inflammatory event were treated at first, and the laboratory tests and clinical measurements were performed on the silent phase. Check up procedures including serum creatinine, liver function tests, total bilirubin value, markers of hepatitis viruses $\mathrm{A}, \mathrm{B}, \mathrm{C}$ and human immunodeficiency virus, a posterior-anterior chest x-ray film, an electrocardiogram, a Doppler echocardiogram both to evaluate cardiac walls and valves and to measure systolic BP of pulmonary artery, an abdominal ultrasonography, a computed tomography of brain, and a magnetic resonance imaging (MRI) of hips were performed. Other bones for avascular necrosis were scanned according to the patients' complaints. So avascular necrosis of bones was diagnosed by means of MRI (8). Systolic BP of the pulmonary artery of $40 \mathrm{mmHg}$ or higher is accepted as pulmonary hypertension (9). The criterion for diagnosis of COPD is post-bronchodilator forced expiratory volume in one second/forced vital capacity of less than $70 \%$ (10). Acute chest syndrome (ACS) is diagnosed clinically with the presence of new infiltrates on chest X-ray film, fever, cough, sputum production, dyspnea, or hypoxia (11). An x-ray film of abdomen in upright position was taken just in patients with abdominal distention or discomfort, vomiting, obstipation, or lack of bowel movement, and ileus is diagnosed with gaseous distention of isolated segments of bowel, vomiting, obstipation, cramps, and with the absence of peristaltic activity on the abdomen. CRD is diagnosed with a persistent serum creatinine level of $1.3 \mathrm{mg} / \mathrm{dL}$ or higher in males and $1.2 \mathrm{mg} / \mathrm{dL}$ or higher in females. Cirrhosis is diagnosed with physical examination findings, laboratory parameters, and ultrasonographic evaluation. An exercise electrocardiogram is performed in cases with an abnormal electrocardiogram and/or angina pectoris. Coronary angiography is taken for the exercise electrocardiogram positive cases. So CHD was diagnosed either angiographically or with the Doppler echocardiographic findings as the movement disorders in the cardiac walls. Rheumatic heart disease (RHD) is diagnosed with the echocardiographic findings, too. Stroke is diagnosed by the computed tomography of brain. Eventually, patients with the total plasma bilirubin value of lower than $5.0 \mathrm{mg} / \mathrm{dL}$ were collected into the first and $5.0 \mathrm{mg} / \mathrm{dL}$ and higher were collected into the second groups, and compared in between. Mann-Whitney U test, Independent-Samples t test, and comparison of proportions were used as the methods of statistical analyses.

\section{Results}

We studied 253 patients (128 females) with the total plasma bilirubin value of lower than $5.0 \mathrm{mg} / \mathrm{dL}$ and 109 patients $(43$ females) with the value of $5.0 \mathrm{mg} / \mathrm{dL}$ and higher. There were 31 death cases during the ten-year follow up period (14 females with a mean age of $33.3 \pm 9.2(19-47)$ and 17 males with a mean age of $30.2 \pm 8.4(19-50)$ years, $p>0.05)$. The mean total bilirubin values of the plasma were 2.7 versus $9.7 \mathrm{mg} / \mathrm{dL}$ in the first and second groups, $\mathrm{p}<0.000$, respectively. The mean ages were similar in the first and second groups (30.2 versus 31.7 years, $\mathrm{p}>0.05$, respectively). Interestingly, male ratio was higher in the second group, significantly $(60.5 \%$ versus $49.4 \%, \mathrm{p}<0.05)$. Similarly, ileus $(3.9 \%$ versus $10.0 \%, \mathrm{p}<0.01)$, digital clubbing $(6.3 \%$ versus $26.6 \%, \mathrm{p}<0.001)$, leg ulcers $(12.2 \%$ versus $20.1 \%$, $\mathrm{p}<0.05)$, pulmonary hypertension $(9.4 \%$ versus $23.8 \%, \mathrm{p}<0.001)$, cirrhosis $(1.5 \%$ versus $15.5 \%, \mathrm{p}<0.001), \mathrm{CRD}(6.7 \%$ versus $12.8 \%, \mathrm{p}<0.05)$, and exitus ( $4.7 \%$ versus $11.9 \%, \mathrm{p}<0.001)$ were all higher in patients with a plasma bilirubin value of $5.0 \mathrm{mg} / \mathrm{dL}$ and higher, significantly. Although the transfused units of RBC in their lives (45.7 versus 37.1 units), CHD (22.0\% versus $16.6 \%)$, COPD (22.9\% versus $16.2 \%)$, RHD (10.0\% versus $6.3 \%)$, AVN (28.4\% versus $24.5 \%)$, disseminated teeth losses $(3.6 \%$ versus 
$2.7 \%$ ), and ACS (5.5\% versus 3.1\%) were also higher in patients with the total plasma bilirubin value of $5.0 \mathrm{mg} / \mathrm{dL}$ and higher, the differences were nonsignificant ( $p>0.05$ for all) probably due to the small sample size of these patients (Table 1).

\section{Discussion}

SCD are chronic inflammatory processes on vascular endothelium terminating with accelerated atherosclerosis induced end-organ failures in early years of life $(12,13)$. Hemoglobin $\mathrm{S}$ $(\mathrm{HbS})$ causes loss of elastic and biconcave disc shaped structures of RBC. Probably loss of elasticity instead of shape is the main pathology since sickling is rare in peripheric blood samples of the SCD patients with associated thalassemia minor, and human survival is not affected in hereditary spherocytosis or elliptocytosis. Loss of elasticity is present during whole lifespan, but exaggerated with inflammations, infections, and various stresses of the body. The hard RBC induced chronic endothelial damage, inflammation, edema, and fibrosis terminate with disseminated tissue hypoxia all over the body (14, 15). As a difference from other causes of chronic endothelial damage, the SCD may keep vascular endothelium particularly at the capillary level (16), since the capillary system is the main distributor of the hard cells into the tissues. The hard cells induced chronic endothelial damage builds up an advanced atherosclerosis in much younger ages of the patients. As a result, mean lifespans of the patients were 48 and 42 years in females and males in the literature, respectively (17), whereas they were 33.3 and 30.2 years in the present study. The great differences may be secondary to delayed diagnosis, delayed initiation of hydroxyurea therapy, and inadequate RBC supports during emergencies in Turkey (18). Actually, RBC supports must be given immediately during all medical or surgical events in which there is evidence of clinical deterioration in the SCD (11). RBC supports decrease sickle cell concentration in circulation and suppress bone marrow for the production of abnormal RBC. So it decreases sickling-induced endothelial damage and inflammation all over the body.

Digital clubbing is characterized by increased normal angle of $165^{\circ}$ between nailbed and fold, increased convexity of the nail fold, and thickening of the whole distal finger (19). The exact cause and significance is unknown but chronic tissue hypoxia is highly suspected (20). In the previous study, only $40 \%$ of clubbing cases turned out to have significant underlying diseases while $60 \%$ remained well over the subsequent years (7). But according to our experiences, digital clubbing is frequently associated with smoking and pulmonary, cardiac, and hepatic disorders which are characterized with chronic tissue hypoxia (3). As an explanation for this hypothesis, lungs, heart, and liver are closely related organs and their functions are affected in a short period of time. On the other hand, digital clubbing is also common in patients with the SCD and its prevalence was $12.4 \%$ in the present study. It probably shows chronic tissue

Table 1: Characteristic features of the study patients

\begin{tabular}{|c|c|c|c|}
\hline Variables & $\begin{array}{c}\text { Cases with a total bilir ubin } \\
\text { value of less than } 5.0 \\
\mathrm{mg} / \mathrm{dL}\end{array}$ & p-value & $\begin{array}{c}\text { Cases with a total bilirubin } \\
\text { value of } 5.0 \mathrm{mg} / \mathrm{dL} \text { a nd } \\
\text { higher }\end{array}$ \\
\hline Number & 253 & & 109 \\
\hline Mean age (year) & $30.2 \pm 10.0(5-59)$ & $\mathrm{Ns}^{*}$ & $31.7 \pm 9.4(15-58)$ \\
\hline Male ratio & $\underline{49.4 \%}$ & $\leq 0.05$ & $60.5 \%$ \\
\hline $\mathrm{BMI}^{+}(\mathrm{lg} / \mathrm{m})$ & $21.7 \pm 3.2(14.3-325)$ & Ns & $21.3 \pm 3.5(14.5-35.8)$ \\
\hline Transfused RBC $\div$ units & $37.1 \pm 47.5(0.339)$ & Ns & $45.7 \pm 63.7(0-434)$ \\
\hline Totalbilirubin (mq/di) & $2.7 \pm 1.0(0.6-4.9)$ & 2.000 & $2.7 \pm 7.3(5-5.2 .2)$ \\
\hline Heus & $\underline{3.9 \%}$ & $\leq 0.01$ & $\underline{10.0 \%}$ \\
\hline Digitalciubbing & $\underline{6.3 \%}$ & $\leq 0.001$ & $\underline{26.6 \%}$ \\
\hline Lequicers & $\underline{12.2 \%}$ & $\leq 0.05$ & $\underline{20.1 \%}$ \\
\hline Puimonary hypertension & $\underline{9.4 \%}$ & $\leq 0.001$ & $23.8 \%$ \\
\hline cirmasis & $1.5 \%$ & $\leq 0,001$ & $15.5 \%$ \\
\hline CROS & $\underline{6.7 \%}$ & $\leq 0.05$ & $\underline{12.8 \%}$ \\
\hline CHDף & $16.6 \%$ & Ns & $22.0 \%$ \\
\hline $\mathrm{COPD}^{* *}$ & $16.2 \%$ & Ns & $22.9 \%$ \\
\hline $\mathrm{RHD}^{*+*}$ & $6.3 \%$ & Ns & $10.0 \%$ \\
\hline $\mathrm{AVN}^{*+* *}$ & $24.5 \%$ & Ns & $20.4 \%$ \\
\hline Strole & $112 \%$ & Ns & $11.0 \%$ \\
\hline $\begin{array}{l}\text { Disseminated teeth losses } \\
\text { (< } 20 \text { teeth present })\end{array}$ & $2.7 \%$ & Ns & $3.6 \%$ \\
\hline $\mathrm{ACS}^{+*+*+\phi}$ & $3.1 \%$ & Ns & $5.5 \%$ \\
\hline Exitus & $4.7 \%$ & $<0.001$ & $11.9 \%$ \\
\hline
\end{tabular}

*Nonsignificant $(\mathrm{p}>0.05) \quad \dagger$ Body mass index $\$$ Red blood cells $\S$ Chronic renal disease $\quad$ TCoronary heart disease ** Chronic obstructive pulmonary disease $* * *$ Rheumatic heart disease $* * * *$ Avascular necrosis of bone *****Acute chest syndrome 
hypoxia caused by disseminated endothelial damage, inflammation, and edema at the capillary level in the SCD. Beside the effects of SCD, the higher prevalences of smoking, COPD, and clubbing in males ( $p<0.001$ for all) may also show some additional roles of smoking, COPD, and male sex on digital clubbing (21).

Leg ulcers are seen in 10 to $20 \%$ of patients with the SCD (20), and the ratio was $14.6 \%$ in the present study. Its incidence increases with age, male sex, and HbSS genotype (22). Similarly, its ratio was higher in males $(19.8 \%$ versus $7.0 \%, \mathrm{p}<0.001)$, and mean age of the patients with leg ulcers was significantly higher than the others $(35.3$ versus 29.8 years, $p<0.000)$ in the above study (21). The leg ulcers have an intractable nature, and around $97 \%$ of healed ulcers relapse in a period of one year (22). As evidence of their atherosclerotic nature, the leg ulcers occur in distal areas with less collateral blood flow in the body (22). The hard RBC induced chronic endothelial damage, inflammation, edema, and fibrosis at the capillary level may be the major cause in the SCD (23). Prolonged exposure to the hard bodies due to the pooling of blood in the lower extremities may also explain the leg but not arm ulcers in the SCD. The hard RBC induced venous insufficiencies may also accelerate the process by pooling of causative hard bodies in the legs, and vice versa. Pooling of blood in the lower extremities may also have some effects on development of venous ulcers, diabetic ulcers, Buerger's disease, digital clubbing, and onychomycosis. Pooling of blood in the lower extremities may also have some effects on the delayed wound and fracture healings in the lower extremities. Beside the hard RBC, smoking and alcohol may also have some additional effects on the leg ulcers since both of them are more common in males. Hydroxyurea is the first drug that was approved by the Food and Drug Administration for the treatment of SCD (16). It is an oral, cheap, safe, and effective drug that blocks cell division by suppressing formation of deoxyribonucleotides which are the building blocks of DNA (18). Its main action may be suppression of hyperproliferative white blood cells (WBC) and platelets (PLT) in the SCD (24). Although presence of continuous damage of hard $\mathrm{RBC}$ on endothelium, severity of the destructive process is probably exaggerated by the patients' own immune systems. Similarly, lower WBC counts were associated with lower crises rates, and if a tissue infarct occurs, lower WBC counts may decrease severity of pain and tissue damage (25). According to our 15-year experience on the SCD, prolonged resolution of leg ulcers with hydroxyurea may also suggest that the leg ulcers may be secondary to increased WBC and PLT counts induced prolonged endothelial damage, inflammation, and edema at the capillary level in the SCD.

Varices are abnormally dilated veins with tortuous courses, and they usually occur in the lower extremities. Related factors include pregnancy, obesity, menopause, aging, and heredity. In other words, varices are more common in females and metabolic syndrome. Normally, leg muscles pump veins to return blood against gravity, and the veins have pairs of leaflets of valves to prevent blood from flowing backwards. When the leaflets are damaged, varices and/or telangiectasias develop. Deep vein thrombosis (DVT) may also cause varicose veins. Varicose veins are the most common in superficial veins of the legs, which are subject to higher pressure when standing up, thus patient's physical examination should be performed in upright position. Although the relatively younger mean ages of the patients in the above study ( 30.8 and 30.3 years in males and females, respectively) (21) and significantly lower BMI of the SCD cases in the literature (15), DVT and/or varices and/or telangiectasias of the lower limbs were higher among the study cases $(9.0 \%$ versus $6.6 \%$ in males and females, respectively, $\mathrm{p}>0.05$ ) indicating an additional venous endothelial involvement in the SCD (21).

Both frequency and complications of cirrhosis are increasing in the world. For example, it was the 10th leading cause of death for men and the 12th for women in the United States in 2001 (4). Although the improvements of health services worldwide, the increased morbidity and mortality of cirrhosis may be explained by aging of the human being and increased prevalence of excess weight all over the world. For example, nonalcoholic fatty liver disease (NAFLD) affects up to one third of the world population, and it has become the most common cause of chronic liver disease even in children and adolescents at the moment $(26,27)$. NAFLD is a marker of pathological fat deposition combined with a low-grade chronic inflammation, which results with hypercoagulability, endothelial dysfunction, and an accelerated atherosclerotic process (26). Besides terminating with cirrhosis, NAFLD is associated with higher overall mortality rates as well as with increased prevalence of cardiovascular diseases (27). Authors reported independent associations between NAFLD and impaired flow-mediated vasodilation and increased mean carotid artery intima-media thickness (CIMT) $(27,28)$. NAFLD and cirrhosis may be considered as the hepatic consequences of the metabolic syndrome (29). Probably smoking also plays a role in the endothelial inflammatory process of the liver, since the systemic inflammatory effects of smoking on endothelial cells is well-known with Buerger's disease and COPD (30). Increased oxidative stresses, inactivation of antiproteases, and release of proinflammatory mediators may terminate with a systemic atherosclerosis in smokers. The atherosclerotic effects of alcohol is much more prominent in hepatic endothelium probably due to the highest concentrations of its metabolites in the liver. Similarly, aging alone may be another cause of systemic atherosclerosis that prevents adequate tissue oxygenation. Chronic infectious and inflammatory processes may also terminate with an accelerated atherosclerosis all over the body (31). For example, chronic hepatitis $\mathrm{C}$ virus infection raised CIMT, and normalisation of hepatic function with viral clearance may be secondary to reversal of favourable lipids observed with the chronic infection (31). As a result, beside COPD, ileus, leg ulcers, digital clubbing, CHD, CRD, and stroke, cirrhosis may also be one of the several consequences of the metabolic syndrome and SCD. The higher total bilirubin values of the plasma may show the severity of hemolytic process initiated at birth and/or an advanced hepatic disease in the present study.

Both frequency and complications of CRD are increasing all over the world, again. For instance, 1.9 to 2.3 millions of people have CRD in Canada (32). The Centers for Disease Control and Prevention in the USA found that CRD affected an estimated 
$16.8 \%$ of adults above the age of 20 years between 1999 and 2004 (33). Similarly, the increased frequency and complications of CRD may be explained by aging of the societies and increased prevalence of excess weight all over the world, since CRD may also be one of the terminal endpoints of the metabolic syndrome, and an eventual advanced atherosclerosis may be the underlying cause of the CRD (34). Aging, sedentary lifestyle, physical inactivity, excess weight, smoking, alcohol, inflammatory and infectious processes, cancers, and SCD may be some triggering causes of the endothelial inflammation in the kidneys. The inflammatory process is enhanced by release of various chemical factors by lymphocytes to repair the damaged renal tissues, especially endothelial cells of the renal arterioles. Due to the continuous irritation of the endothelial cells in the above pathologies, prominent changes develop in the architecture of the renal tissues with advanced atherosclerosis, fibrosis, and tissue hypoxia and infarcts. Excess weight induced metabolic abnormalities such as hyperglycemia, dyslipidemia, elevated $\mathrm{BP}$, and insulin resistance cause various cellular stresses which accelerate tissue inflammation and immune cell activation further (35). For example, age $(p=0.04)$, high-sensitivity C-reactive protein $(p=0.01)$, mean arterial BP $(p=0.003)$, and DM $(p=0.02)$ had significant correlations with CIMT (34). Increased renal tubular sodium reabsorption, impaired pressure natriuresis, volume expansion due to the activation of sympathetic nervous system and renin-angiotensin system, and physical compression of kidneys by visceral fat tissue may be some mechanisms of the increased BP with excess weight (36). Excess weight also causes renal vasodilation and glomerular hyperfiltration which initially serve as compensatory mechanisms to maintain sodium balance due to the increased tubular reabsorption (36). However, along with the increased BP, these changes cause a hemodynamic burden on the kidneys in the long term that causes chronic endothelial damage (37). With prolonged weight excess, there are increased urinary protein excretion, lost nephron function, and exacerbated HT. With the development of dyslipidemia and DM in the overweight and obese individuals, CRD progresses much more rapidly (36). On the other hand, the systemic inflammatory effects of smoking on endothelial cells may also be important in the etiology of CRD (38). The inflammatory and eventual atherosclerotic effects of smoking are much more prominent in the respiratory endothelium due to the highest concentrations of its metabolites there. Although some authors reported that alcohol was not related with the CRD (38), it is not logical since various metabolites of alcohol circulate even in the blood vessels of the kidneys and give harm to the vascular endothelium, there. Similarly, aging alone may be another cause of the CRD by means of the systemic atherosclerotic effects. Chronic inflammatory or infectious processes may also terminate with the accelerated atherosclerosis on the renal endothelium (31). Although CRD is mainly an advanced atherosclerotic process of the renal vasculature, there are close relationships between CRD and other consequences of the metabolic syndrome including CHD, COPD, PAD, cirrhosis, and stroke (39). For example, the most common cause of death in the CRD is cardiovascular diseases rather than the renal failure again (40). In another definition, CRD may actually be one of the several consequences of the metabolic syndrome and SCD, again.
COPD is the third leading cause of death with various causes in the world (41). It is an inflammatory disease that mainly affects the pulmonary vasculature. Aging, smoking, and excess weight may be the major underlying causes. As also observed in the study, alcohol may also be an important cause in the inflammatory process (42). For example, COPD was one of the most common diagnoses in patients with alcohol dependence (43). Furthermore, 30-day readmission rates were higher in the COPD patients with alcoholism (44). Probably an accelerated atherosclerotic process is the main structural background of functional changes, characteristics of the COPD. The inflammatory process of vascular endothelium is enhanced by release of various chemicals by inflammatory cells, and it terminates with an advanced fibrosis, atherosclerosis, and pulmonary losses. Although the COPD may mainly be an accelerated atherosclerotic process of the pulmonary vasculature, there are several reports about coexistence of associated endothelial inflammation all over the body $(45,46)$. For instance, there may be close relationships between COPD, CHD, PAD, and stroke (47). Furthermore, two-thirds of mortality cases were caused by cardiovascular diseases and lung cancers in the COPD, and the CHD was the most common cause in a multi-center study of 5.887 smokers (48). When the hospitalizations were researched, the most common causes were the cardiovascular diseases again (48). In another study, $27 \%$ of all mortality cases were due to the cardiovascular diseases in the moderate and severe COPD patients (49). Similarly, COPD may also be one of the terminal endpoints of the SCD due to the higher prevalence of COPD associated with priapism, leg ulcers, clubbing, CHD, CRD, and stroke (50).

Probably pulmonary hypertension is also found among the atherosclerotic endpoints of the SCD. It is defined as the increased BP in pulmonary artery, vein, or capillaries. It is seen in $60 \%$ of systemic sclerosis, $40 \%$ of SCD, $14 \%$ of systemic lupus erythematosus, $21 \%$ of rheumatoid arthritis, $5 \%$ of portal hypertension, and $0.5 \%$ of human immunodeficiency virus infected patients (51). Whereas we detected pulmonary hypertension just in $12.2 \%$ of the SCD patients in the above study (42). Younger mean ages of the study cases (30.6 \pm 9.8 years) may be the main cause of the lower prevalence (42). Pulmonary hypertension and COPD may actually have similar atherosclerotic underlying mechanisms during the development but pulmonary hypertension may be a more advanced disease since its mean age is higher (34.0 versus 33.6 years), prevalence is lower $(12.2 \%$ versus $16.3 \%)$, and it is nearly equally seen in both genders compared to COPD (52.8\% versus $78.8 \%$ in males) (42). On the other hand, venous pulmonary hypertension is the most common type in society (52). In venous pulmonary hypertension, the left heart fails to pump blood efficiently, leading to pooling of blood in the lungs. This causes pulmonary edema and pleural effusions. In chronic thromboembolic pulmonary hypertension, blood vessels are blocked or narrowed with clots, which leads to a similar pathophysiology with arterial pulmonary hypertension (53). In hypoxic pulmonary hypertension, hypoxia is thought to cause vasoconstriction or tightening of pulmonary arteries. This pathophysiology may also be the major underlying mechanism in the SCD due to the inflammated and edematous capillary endothelium, secondary to the damage of abnormally hardened RBC in the lungs (54). 
Whatever the initial cause, pulmonary hypertension involves vasoconstriction and tightening of blood vessels connected to and within lungs. This further increases BP within lungs and impairs their blood flow. Eventually, increased workload of heart causes thickening and enlargement of right ventricle, right heart failure, and cor pulmonale. As blood flowing through lungs decreases, left heart receives less blood. This blood may also carry less oxygen than normal as in the SCD due to the capillary endothelial inflammation and edema. Thus it becomes harder and harder for the left heart to pump sufficient oxygen to the rest of body, particularly during physical activities. Although various arterial and venous involvement mechanisms, capillary endothelial involvement may be the major underlying cause of pulmonary hypertension in the SCD since the capillary system is the main distributor of the abnormally hardened RBC into the lungs.

As a conclusion, SCD are severe inflammatory processes on vascular endothelium, particularly at the capillary level and terminate with accelerated atherosclerosis induced end-organ failures in early years of life. Total bilirubin value of the plasma may have prognostic significance due to the higher prevalence of ileus, digital clubbing, leg ulcers, pulmonary hypertension, cirrhosis, CRD, and exitus in patients with the plasma bilirubin value of $5.0 \mathrm{mg} / \mathrm{dL}$ and higher. The higher bilirubin values may either show the severity of hemolytic process initiated at birth or an advanced hepatic involvement in such cases.

\section{References}

1. Eckel RH, Grundy SM, Zimmet PZ. The metabolic syndrome. Lancet 2005; 365(9468): 1415-1428.

2. Helvaci MR, Kaya H, Sevinc A, Camci C. Body weight and white coat hypertension. Pak J Med Sci 2009; 25(6): 916921.

3. Helvaci MR, Aydin LY, Aydin Y. Digital clubbing may be an indicator of systemic atherosclerosis even at microvascular level. HealthMED 2012; 6(12): 3977-3981.

4. Anderson RN, Smith BL. Deaths: leading causes for 2001. Natl Vital Stat Rep 2003; 52(9): 1-85.

5. Third Report of the National Cholesterol Education Program (NCEP) Expert Panel on Detection, Evaluation, and Treatment of High Blood Cholesterol in Adults (Adult Treatment Panel III) final report. Circulation 2002; 106(25): 31433421.

6. Vandemergel X, Renneboog B. Prevalence, aetiologies and significance of clubbing in a department of general internal medicine. Eur J Intern Med 2008; 19(5): 325-329.

$7 . \quad$ Schamroth L. Personal experience. S Afr Med J 1976; 50(9): 297-300.

8. Mankad VN, Williams JP, Harpen MD, Manci E, Longenecker G, Moore RB, et al. Magnetic resonance imaging of bone marrow in sickle cell disease: clinical, hematologic, and pathologic correlations. Blood 1990; 75(1): 274-283.

9. Fisher MR, Forfia PR, Chamera E, Housten-Harris T, Champion HC, Girgis RE, et al. Accuracy of Doppler echocardiography in the hemodynamic assessment of pulmonary hy- pertension. Am J Respir Crit Care Med 2009; 179(7): 615-621.

10. Vestbo J, Hurd SS, Agustí AG, Jones PW, Vogelmeier C, Anzueto A, et al. Global strategy for the diagnosis, management, and prevention of chronic obstructive pulmonary disease: GOLD executive summary. Am J Respir Crit Care Med 2013; 187(4): 347-365.

11. Davies SC, Luce PJ, Win AA, Riordan JF, Brozovic M. Acute chest syndrome in sickle-cell disease. Lancet 1984; 1(8367): 36-38.

12. Helvaci MR, Yaprak M, Abyad A, Pocock L. Atherosclerotic background of hepatosteatosis in sickle cell diseases. World Family Med 2018; 16(3): 12-18.

13. Helvaci MR, Davarci M, Inci M, Yaprak M, Abyad A, Pocock L. Chronic endothelial inflammation and priapism in sickle cell diseases. World Family Med 2018; 16(4): 6-11.

14. Helvaci MR, Gokce C, Davran R, Akkucuk S, Ugur M, Oruc C. Mortal quintet of sickle cell diseases. Int J Clin Exp Med 2015; 8(7): 11442-11448.

15. Helvaci MR, Kaya H. Effect of sickle cell diseases on height and weight. Pak J Med Sci 2011; 27(2): 361-364.

16. Yawn BP, Buchanan GR, Afenyi-Annan AN, Ballas SK, Hassell KL, James AH, et al. Management of sickle cell disease: summary of the 2014 evidence-based report by expert panel members. JAMA 2014; 312(10): 1033-1048.

17. Platt OS, Brambilla DJ, Rosse WF, Milner PF, Castro $\mathrm{O}$, Steinberg $\mathrm{MH}$, et al. Mortality in sickle cell disease. Life expectancy and risk factors for early death. N Engl J Med 1994; 330(23): 1639-1644.

18. Helvaci MR, Aydin Y, Ayyildiz O. Hydroxyurea may prolong survival of sickle cell patients by decreasing frequency of painful crises. HealthMED 2013; 7(8): 2327-2332.

19. Myers KA, Farquhar DR. The rational clinical examination. Does this patient have clubbing? JAMA 2001; 286(3): 341-347.

20. Toovey OT, Eisenhauer HJ. A new hypothesis on the mechanism of digital clubbing secondary to pulmonary pathologies. Med Hypotheses 2010; 75(6): 511-513.

21. Helvaci MR, Tekin B, Abyad A, Pocock L. Alarming consequences of the sickle cell diseases. World Family Med 2018; 16(7): 14-21.

22. Trent JT, Kirsner RS. Leg ulcers in sickle cell disease. Adv Skin Wound Care 2004: 17(8); 410-416.

23. Minniti CP, Eckman J, Sebastiani P, Steinberg MH, Ballas SK. Leg ulcers in sickle cell disease. Am J Hematol 2010; 85(10): 831-833.

24. Helvaci MR, Aydogan F, Sevinc A, Camci C, Dilek I. Platelet and white blood cell counts in severity of sickle cell diseases. Pren Med Argent 2014; 100(1): 49-56.

25. Charache S. Mechanism of action of hydroxyurea in the management of sickle cell anemia in adults. Semin Hematol 1997; 34(3): 15-21.

26. Bhatia LS, Curzen NP, Calder PC, Byrne CD. Non-alcoholic fatty liver disease: a new and important cardiovascular risk factor? Eur Heart J 2012; 33(10): 1190-1200. 
27. Pacifico L, Nobili V, Anania C, Verdecchia P, Chiesa C. Pediatric nonalcoholic fatty liver disease, metabolic syndrome and cardiovascular risk. World J Gastroenterol 2011; 17(26): 3082-3091.

28. Mawatari S, Uto H, Tsubouchi H. Chronic liver disease and arteriosclerosis. Nihon Rinsho 2011; 69(1): 153-157.

29. Bugianesi E, Moscatiello S, Ciaravella MF, Marchesini G. Insulin resistance in nonalcoholic fatty liver disease. Curr Pharm Des 2010; 16(17): 1941-1951.

30. Helvaci MR, Aydin LY, Aydin Y. Chronic obstructive pulmonary disease may be one of the terminal end points of metabolic syndrome. Pak J Med Sci 2012; 28(3): 376-379.

31. Mostafa A, Mohamed MK, Saeed M, Hasan A, Fontanet A, Godsland I, et al. Hepatitis C infection and clearance: impact on atherosclerosis and cardiometabolic risk factors. Gut 2010; 59(8): 1135-1140.

32. Levin A, Hemmelgarn B, Culleton B, Tobe S, McFarlane P, Ruzicka M, et al. Guidelines for the management of chronic kidney disease. CMAJ 2008; 179(11): 1154-1162.

33. Centers for Disease Control and Prevention (CDC). Prevalence of chronic kidney disease and associated risk factors--United States, 1999-2004. MMWR Morb Mortal Wkly Rep 2007; 56(8): 161-165.

34. Nassiri AA, Hakemi MS, Asadzadeh R, Faizei AM, Alatab S, Miri R, et al. Differences in cardiovascular disease risk factors associated with maximum and mean carotid intima-media thickness among hemodialysis patients. Iran J Kidney Dis 2012; 6(3): 203-208.

35. Xia M, Guerra N, Sukhova GK, Yang K, Miller CK, Shi GP, et al. Immune activation resulting from NKG2D/ligand interaction promotes atherosclerosis. Circulation 2011; 124(25): 2933-2943.

36. Hall JE, Henegar JR, Dwyer TM, Liu J, da Silva AA, Kuo JJ, et al. Is obesity a major cause of chronic kidney disease? Adv Ren Replace Ther 2004; 11(1): 41-54.

37. Nerpin E, Ingelsson E, Risérus U, HelmerssonKarlqvist J, Sundström J, Jobs E, et al. Association between glomerular filtration rate and endothelial function in an elderly community cohort. Atherosclerosis 2012; 224(1): 242-246.

38. Stengel B, Tarver-Carr ME, Powe NR, Eberhardt MS, Brancati FL. Lifestyle factors, obesity and the risk of chronic kidney disease. Epidemiology 2003; 14(4): 479-487.

39. Bonora E, Targher G. Increased risk of cardiovascular disease and chronic kidney disease in NAFLD. Nat Rev Gastroenterol Hepatol 2012; 9(7): 372-381.

40. Tonelli M, Wiebe N, Culleton B, House A, Rabbat C, Fok M, et al. Chronic kidney disease and mortality risk: a systematic review. J Am Soc Nephrol 2006; 17(7): 2034-2047.

41. Rennard SI, Drummond MB. Early chronic obstructive pulmonary disease: definition, assessment, and prevention. Lancet 2015; 385(9979): 1778-1788.

42. Helvaci MR, Arslanoglu Z, Celikel A, Abyad A, Pocock L. Pathophysiology of pulmonary hypertension in sickle cell diseases. Middle East J Intern Med 2018; 11(2): 14-21.

43. Schoepf D, Heun R. Alcohol dependence and physical comorbidity: Increased prevalence but reduced relevance of individual comorbidities for hospital-based mortality during a 12.5-year observation period in general hospital admissions in urban North-West England. Eur Psychiatry 2015; 30(4): 459468.

44. Singh G, Zhang W, Kuo YF, Sharma G. Association of Psychological Disorders With 30-Day Readmission Rates in Patients With COPD. Chest 2016; 149(4): 905-915.

45. Danesh J, Collins R, Appleby P, Peto R. Association of fibrinogen, C-reactive protein, albumin, or leukocyte count with coronary heart disease: meta-analyses of prospective studies. JAMA 1998; 279(18): 1477-1482.

46. Mannino DM, Watt G, Hole D, Gillis C, Hart C, McConnachie A, et al. The natural history of chronic obstructive pulmonary disease. Eur Respir J 2006; 27(3): 627-643.

47. Mapel DW, Hurley JS, Frost FJ, Petersen HV, Picchi MA, Coultas DB. Health care utilization in chronic obstructive pulmonary disease. A case-control study in a health maintenance organization. Arch Intern Med 2000; 160(17): 2653 2658.

48. Anthonisen NR, Connett JE, Enright PL, Manfreda J; Lung Health Study Research Group. Hospitalizations and mortality in the Lung Health Study. Am J Respir Crit Care Med 2002; 166(3): 333-339.

49. McGarvey LP, John M, Anderson JA, Zvarich M, Wise RA; TORCH Clinical Endpoint Committee. Ascertainment of cause-specific mortality in COPD: operations of the TORCH Clinical Endpoint Committee. Thorax 2007; 62(5): 411-415.

50. Helvaci MR, Erden ES, Aydin LY. Atherosclerotic background of chronic obstructive pulmonary disease in sickle cell patients. HealthMED 2013; 7(2): 484-488.

51. Simonneau G, Robbins IM, Beghetti M, Channick RN, Delcroix M, Denton CP, et al. Updated clinical classification of pulmonary hypertension. J Am Coll Cardiol 2009; 54(1): 43-54

52. Duffels MG, Engelfriet PM, Berger RM, van Loon RL, Hoendermis E, Vriend JW, et al. Pulmonary arterial hypertension in congenital heart disease: an epidemiologic perspective from a Dutch registry. Int J Cardiol 2007; 120(2): 198204.

53. Oudiz RJ. Classification of pulmonary hypertension. Cardiol Clin 2016; 34(3): 359-361.

54. Gladwin MT, Sachdev V, Jison ML, Shizukuda Y, Plehn JF, Minter K, et al. Pulmonary hypertension as a risk factor for death in patients with sickle cell disease. N Engl J Med 2004; 350(9): 886-895. 